\title{
Resonant and a new disturbance-observer combined control for off-grid voltage source inverter
}

\author{
Marco di Benedetto ${ }^{1}$, Mi Tang ${ }^{2}$, Alessandro Lidozzi ${ }^{1}$, Luca Solero ${ }^{1}$, Andrea Formentini ${ }^{3}$, \\ Pericle Zannchetta ${ }^{2,4}$ \\ ${ }^{1}$ Department of Engineering, Center for Power Electronics and Drives (C-PED), Roma Tre University, Roma, Italy \\ ${ }^{2}$ Department of Electrical and Electronics Engineering, University of Nottingham, Nottingham, United Kingdom \\ ${ }^{3}$ Electrical, Electronics and Telecommunication Engineering and Naval Architecture Department (DITEN), University of Genova, \\ Genova, Italy \\ ${ }^{4}$ Department of Engineering, University of Pavia, Pavia, Italy
}

\begin{tabular}{l} 
Article Info \\
\hline Article history: \\
Received Jan 17, 2021 \\
Revised Jan 31, 2022 \\
Accepted Feb 10, 2022 \\
\hline
\end{tabular}

Keywords:

Repetitive observer

Resonant controllers

Three-phase four-leg inverter non-linear loads

Total harmonic distortion

\begin{abstract}
A new control strategy that combines the resonant controller and the repetitive-controller based on the disturbance-observer (RSCDO) for offgrid four-leg voltage source inverter (VSI) has been presented in this paper. The aim of the new controller is to regulate the inverter output voltage, reducing as much as possible the voltage total harmonic distortion (THDv) in every load condition. The resonant controller allows to adjust the voltage at the fundamental harmonic, while the repetitive observer is able to compensate the voltage distortions due to inverter nonlinearity. The proposed strategy has been at first validated by means of simulation results performed in MATLAB/Simulink environment. Then, the new control strategy has been implemented in field-programmable gate array (FPGA) using LabView environmental and experimental results are performed on the $40 \mathrm{kVA}$ three-phase 4-leg VSI prototype.
\end{abstract}

This is an open access article under the CC BY-SA license.

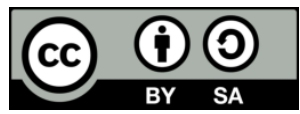

\section{Corresponding Author:}

Marco di Benedetto

Department of Engineering, Center for Power Electronics and Drives (C-PED), Roma Tre University

Via della Vasca Navale 79, 00146 Roma, Italy

Email: marco.dibenedetto@uniroma3.it

\section{INTRODUCTION}

The increasing penetration of renewable energy (especially photovoltaic, wind, and micro-turbine), and the growing need for reliability and power quality in the distributed generation (DG) units has, in the last few years, drawn more attention to direct current (DC) microgrids [1]-[3]. Compared to the alternating current (AC) distribution grids, the DC microgrids have several advantages [4]. In fact, thanks to the use of more efficient power electronic converter to connect the common DC-bus and DC sources, such as photovoltaic (PV), energy storage (ES), wind system, makes the distribution systems more efficient, and economical. A typical stand-alone DC microgrid is illustrated in Figure 1. In DC microgrids, the DC/DC converters can play an important role in the control of the DC-bus voltage and in maintaining the system power balance [5]. AC/DC converters, instead, are mainly used to manage the flow of power generated by micro-turbines and wind turbines. Another very important role is played by the DC/AC converter which is responsible for supplying the load starting from the DC-bus [6]-[9]. DC/AC conversion systems require high performance to ensure highly efficient utilization of DG units [10], [11]. Additionally, the quality of the voltage and current provided by the DG units must satisfy several international requirements, like EN-50160 and electromagnetic compatibility (EMC) EN-61000 [12]. In order to fulfill the mentioned standards, attention is paid to both the converter and the output filter employed in the DG units, as well as to the control 
loop used to regulate the converter. Many converter topologies in combination with output filters have been proposed in literature with the aim to enhance the quality of the output voltage [13].

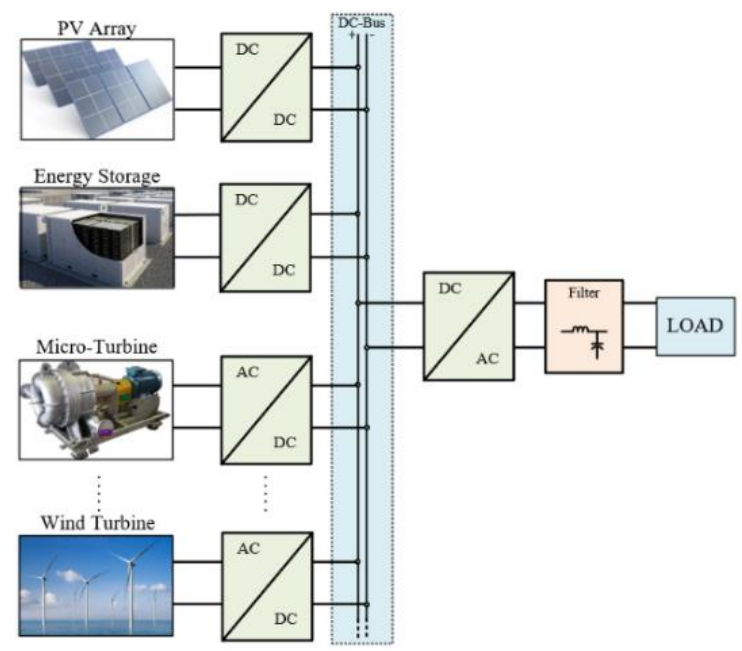

Figure 1. Block diagram of stand-alone microgrid

Obviously, changing in the converter topology can lead to greater use of power semiconductors, which results in a greater effort in tuning of the control algorithm [14]. Different control architectures have been proposed in the literature with the purpose to control the four-leg voltage source inverter (4L VSI) [15][19]. Kumar et al. in [15], the control strategy based on the proportional resonant controller (RSC) has been implemented for grid-connected and stand-alone photovoltaic application. A specific solution to decrease the periodic harmonics, which uses repetitive controller is shown in [16], [17]. In such a system, the repetitive controller assists the conventional feedback controller, and it works only on the harmonics suppression. The repetitive controller and the resonant controller are used in combination in [18]. In this case, the resonant controller can track the sinusoidal reference voltage at fundamental frequency, while the repetitive controller is able to adjust the other harmonics of the voltage to reduce the total harmonic distortion (THD). Lidozzi et al. in [19], the repetitive control works together with the deadbeat control. Deadbeat control is used to rapidly compensate the load variation and the repetitive controller provides the harmonics compensation. In any case, the voltage or the current provided by the VSI are affected by harmonics due to the effects of non-linear loads, devices dead time and modulation. The disturbance-observer (DO) concept has been introduced in order to assist the feedback controller [15]-[19] given that the harmonics could be shaped as disturbances. Ali et al. in [20], a disturbance observer is designed according to the minimum amount of plant information and is used together with proportional controller. Zhu and Fei in [21], instead, the DO is combined with the sliding mode controller in photovoltaic applications. In this case, the DO has been designed to estimate the parameters' variations in the photovoltaic system. Furthermore, in order to improve the tracking accuracy and to reduce the harmonic distortions on the inverter's output voltage, an internal model-based disturbance observer has been clearly discussed in [22]. The repetitive controller and the feedforward are considered similar been highlighted [23]. The DO proposed in [23] acts as a classical repetitive controller by limiting the periodic harmonics. In this case, good performances are obtained in a wide range of stability margins. The tuning of the proposed DO occurs like the classical DO. When compared to the repetitive controller, the new DO can offer the same harmonics suppression performance, and it is easier to tune. It can be added directly to any existing feedback control system without causing instability. When compared to the conventional DO, the new DO can observe a wider range of harmonics up to the Nyquist frequency. In this paper, a new control structure composed by the RSC and the new resonant-controller-like DO is applied to a stand-alone 4L VSI in order to improve the power quality of the output voltage and to obtain an excellent dynamic response. Figure 2 shows the block diagram of the proposed new control strategy. The regulator of the inverter control consists of the RSC and the new DO. The tracking of the reference voltage fundamental harmonic is done by the RSC, whereas the DO takes care of removing the DO takes care of removing all harmonics generated by the non-linear loads, unbalancing loads and the modulation of the VSI, including the dead-time. In this paper the stability analysis of the controller has been discussed, the experimental results have been addressed in more detailed considering the unbalancing and non-linear loads, as well as the transient response of the 
control algorithm has been carried out and a brief comparison with other control strategy has been given. As it will be shown in the paper, the RSC plus DO (RSC-DO) provides good dynamic and steady-state performance compared to the control strategy proposed in [18], [19]. As illustrated in [19], the voltage waveforms are not symmetrical when the controller is enabled. The proposed control avoids the voltage unbalance, and the currents are symmetrical in all load conditions. The paper is organized is being as. Section 2 deals with the inverter topology and output filter description including their transfer functions. Section 3 presents the proposed control strategy and the analysis of both the RSC and the DO, as well as the stability analysis. In section 4 and section 5 the simulation and experimental tests based on $40 \mathrm{kVA} 4 \mathrm{~L}$ VSI prototype are illustrated. Conclusions are finally presented in section 6.

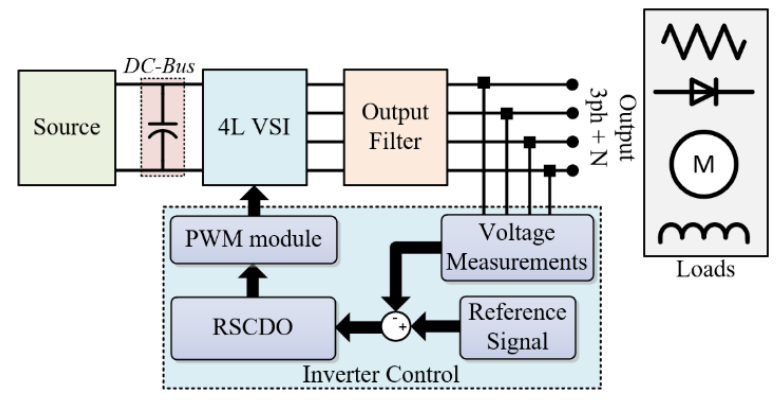

Figure 2. Schematic of the control algorithm for off-grid 4L VSI

\section{CONVERSION SYSTEM DESCRIPTION}

The elimination of the transformer in the stand-alone DC microgrid applications is one of the goals given that the size and the weight of the overall structure are reduced. Without the transformer it is imperative to implement an alternative way to connect the neutral terminal given that since the current flowing in three-phase loads may be unbalanced. There are two ways of connecting the neutral terminal: the first one is to connect it in the middle leg of the DC-bus capacitors, as shown in Figure 3 (a); the second one is to connect it in the middle of the added leg [24], [25], as illustrated in Figure 3 (b).

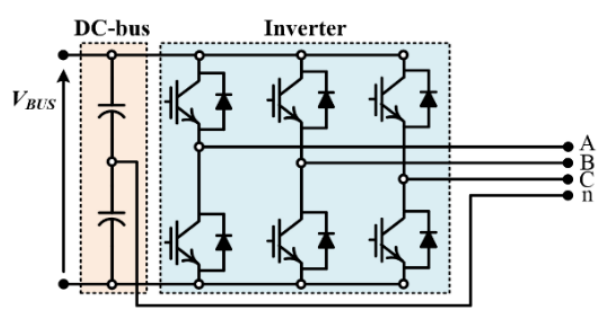

(a)

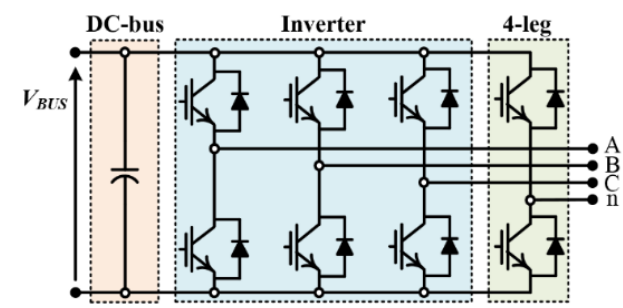

(b)

Figure 3. Neutral terminal connection (a) four-wire topology and (b) four-leg topology

Even if the four wire VSI presents a simple solution, it features several problems. In fact, the voltages across the capacitors may be different and using the sinusoidal pulse-width modulation (PWM) with third harmonic injection, the $3^{\text {rd }}$ harmonic in phase-to-neutral voltages is not canceled. The mentioned problems are fixed by the the four-leg VSI topology. However, by adding a leg with two switches and two diodes involves the addition of driver circuits.

\subsection{Four-leg voltage source inverter topology}

The VSI converters need control circuits to ensure the best input and output characteristics. Switching converter topologies are nonlinear systems due to the presence of power semiconductors [14]. Consequently, it is not easy to forecast their dynamic characteristics. The linearization of the power converter behavior is at the basis of a more predictable tuning procedure of the related control loops. As discussed in [18], the VSI transfer function (TF) of the phase-to-neutral peak output voltage to the peak modulation signal is given in (1), where $\mathrm{V}_{\mathrm{BUS}}$ is the DC-bus voltage, $\mathrm{k}$ is the modulation strategy factor and $\mathrm{f}_{\mathrm{sw}}$ is the switching frequency. According to the sinusoidal PWM with third harmonic injection, the gain $\mathrm{k}_{\text {gain }}$ is 0.57 . 
$\mathrm{G}_{4 \mathrm{~L}}(\mathrm{~s})=\mathrm{k}_{\text {gain }} \frac{\mathrm{V}_{\mathrm{BUS}}}{1+\frac{\mathrm{s}}{2 \pi \mathrm{f}_{\mathrm{sw}}}}$

\subsection{Output filter configuration}

The three-phase output filter is properly designed and realized to reduce the switching harmonic components from the voltage and current waveforms. The electrical circuit of the single-phase output filter is illustrated in Figure 4. There are three branches: 1) the main filter $\left.L_{f}, C_{f}, 2\right)$ the selective damper $\left(R_{d}, L_{d}, C_{d}\right)$, and 3$)$ the trap $\left(\mathrm{R}_{\mathrm{f}}, \mathrm{L}_{\mathrm{f}}, \mathrm{C}_{\mathrm{f}}\right)$.

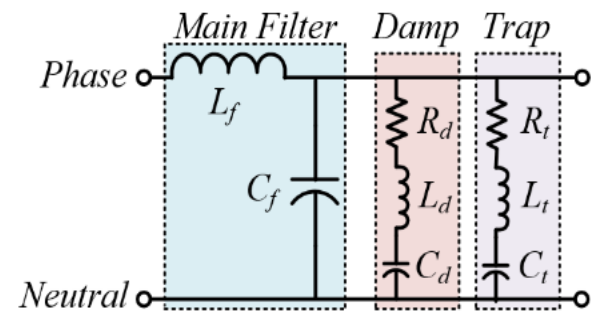

Figure 4. Electrical circuit of the single-phase output filter

The resonant peak provided by the main filter $\mathrm{L}_{f} \mathrm{C}_{\mathrm{f}}$ is damped by the $\mathrm{L}_{d} \mathrm{C}_{\mathrm{d}} \mathrm{R}_{\mathrm{d}}$ branch. This latter has a resonant frequency equal to 1.2 times the main filter $\mathrm{L}_{f} \mathrm{C}_{f}$ resonance frequency. The resistor $\mathrm{R}_{\mathrm{d}}$ acts only in a narrow range of the frequency. Switching harmonics are strongly reduced by the trap branch $\mathrm{R}_{\mathrm{f}}, \mathrm{L}_{\mathrm{f}}$, and $\mathrm{C}_{\mathrm{f}}$. Based on the filter design illustrated in [26], the optimized output filter parameters are: $\mathrm{L}_{\mathrm{f}}=800 \mu \mathrm{H}, \mathrm{C}_{\mathrm{f}}=5 \mu \mathrm{F}$, $\mathrm{L}_{\mathrm{d}}=810 \mu \mathrm{H}, \mathrm{C}_{\mathrm{d}}=7.2 \mu \mathrm{H}, \mathrm{R}_{\mathrm{d}}=20 \Omega, \mathrm{L}_{\mathrm{t}}=138.5 \mu \mathrm{H}, \mathrm{C}_{\mathrm{t}}=1.2 \mu \mathrm{H}$, and $\mathrm{R}_{\mathrm{t}}=60 \mathrm{~m} \Omega$. The transfer function of the output voltage to the input voltage of the output filter can be derived as in (2),

$$
\mathrm{G}_{\mathrm{F}}(\mathrm{s})=\frac{1}{\mathrm{C}_{\mathrm{f}} \mathrm{L}_{\mathrm{f}}} \frac{\mathrm{s}^{4}+\mathrm{a}_{3} \mathrm{~s}^{3}+\mathrm{a}_{2} \mathrm{~s}^{2}+\mathrm{b}_{1} \mathrm{~s}^{5}+\mathrm{b}_{4} \mathrm{~s}^{4}+\mathrm{a}_{3} \mathrm{~s}^{3}+\mathrm{b}_{2} \mathrm{~s}^{2}+\mathrm{b}_{1} \mathrm{~s}+\mathrm{b}_{0}}{\mathrm{~s}}
$$

The TF coefficients of the filter and the distance to fault (DTF) parameters $\mathrm{k}_{\mathrm{RSC}}, \mathrm{a}_{\mathrm{RSC} 0}, \mathrm{a}_{\mathrm{RSC}}, \mathrm{b}_{\mathrm{RSC} 0}$, and $\mathrm{b}_{\mathrm{RSC} 1}$ are listed below.

$$
\begin{aligned}
& \mathrm{a}_{0}=\frac{1}{\mathrm{C}_{\mathrm{d}} \mathrm{C}_{\mathrm{t}} \mathrm{L}_{\mathrm{t}}}, \mathrm{a}_{1}=\frac{1}{\mathrm{~L}_{\mathrm{d}} \mathrm{L}_{\mathrm{t}}}\left(\frac{\mathrm{R}_{\mathrm{d}}}{\mathrm{C}_{\mathrm{t}}}+\frac{\mathrm{R}_{\mathrm{t}}}{\mathrm{C}_{\mathrm{d}}}\right), \mathrm{a}_{2}=\frac{\mathrm{R}_{\mathrm{d}} \mathrm{R}_{\mathrm{t}}}{\mathrm{L}_{\mathrm{d}} \mathrm{L}_{\mathrm{t}}}+\frac{1}{\mathrm{C}_{\mathrm{t}} \mathrm{L}_{\mathrm{t}}}+\frac{1}{\mathrm{C}_{\mathrm{d}} \mathrm{L}_{\mathrm{d}}}, \mathrm{a}_{3}=\frac{\mathrm{R}_{\mathrm{t}}}{\mathrm{L}_{\mathrm{t}}}+\frac{\mathrm{R}_{\mathrm{d}}}{\mathrm{L}_{\mathrm{d}}}, \mathrm{b}_{0}=\frac{1}{\mathrm{C}_{\mathrm{d}} \mathrm{C}_{\mathrm{f}} \mathrm{C}_{\mathrm{t}} \mathrm{L}_{\mathrm{d}} \mathrm{L}_{\mathrm{f}} \mathrm{L}_{\mathrm{t}}} \frac{1}{\mathrm{C}_{\mathrm{f}} \mathrm{L}_{\mathrm{d}} \mathrm{L}_{\mathrm{f}} \mathrm{L}_{\mathrm{t}}}\left(\frac{\mathrm{R}_{\mathrm{d}}}{\mathrm{C}_{\mathrm{t}}}+\frac{\mathrm{R}_{\mathrm{t}}}{\mathrm{C}_{\mathrm{d}}}\right), \mathrm{b}_{2}=\frac{1}{\mathrm{C}_{\mathrm{f}} \mathrm{C}_{\mathrm{t}} \mathrm{L}_{\mathrm{f}} \mathrm{L}_{\mathrm{t}}}+\frac{1}{\mathrm{C}_{\mathrm{f}} \mathrm{C}_{\mathrm{t}} \mathrm{L}_{\mathrm{d}} \mathrm{L}_{\mathrm{t}}}+\frac{1}{\mathrm{C}_{\mathrm{d}} \mathrm{C}_{\mathrm{t}} \mathrm{L}_{\mathrm{d}} \mathrm{L}_{\mathrm{t}}}+\frac{1}{\mathrm{C}_{\mathrm{d}} \mathrm{C}_{\mathrm{f}} \mathrm{L}_{\mathrm{d}} \mathrm{L}_{\mathrm{t}}}+\frac{1}{\mathrm{C}_{\mathrm{t}} \mathrm{L}_{\mathrm{d}} \mathrm{L}_{\mathrm{t}} \mathrm{C}_{\mathrm{d}} \mathrm{L}_{\mathrm{f}}}+\frac{\mathrm{R}_{\mathrm{d}} \mathrm{R}_{\mathrm{t}}}{\mathrm{C}_{\mathrm{f}} \mathrm{L}_{\mathrm{d}} \mathrm{L}_{\mathrm{f}} \mathrm{L}_{\mathrm{t}}} \\
& \mathrm{b}_{4}=\frac{1}{\mathrm{C}_{\mathrm{t}} \mathrm{L}_{\mathrm{t}}}+\frac{1}{\mathrm{C}_{\mathrm{f}} \mathrm{L}_{\mathrm{f}}}+\frac{1}{\mathrm{C}_{\mathrm{f}} \mathrm{L}_{\mathrm{f}} \mathrm{L}_{\mathrm{t}}}+\frac{\mathrm{R}_{\mathrm{d}}}{\mathrm{C}_{\mathrm{f}} \mathrm{L}_{\mathrm{d}} \mathrm{L}_{\mathrm{t}}}+\frac{1}{\mathrm{C}_{\mathrm{d}} \mathrm{L}_{\mathrm{f}}}+\frac{\mathrm{R}_{\mathrm{t}}}{\mathrm{C}_{\mathrm{f}} \mathrm{L}_{\mathrm{t}}}+\frac{\mathrm{R}_{\mathrm{t}}}{\mathrm{L}_{\mathrm{d}}}, \mathrm{b}_{5}=\frac{\mathrm{R}_{\mathrm{t}}}{\mathrm{L}_{\mathrm{t}}}+\frac{\mathrm{R}_{\mathrm{d}}}{\mathrm{L}_{\mathrm{d}}},
\end{aligned}
$$

\section{PROPOSED CONTROL STRATEGY}

The proposed control strategy is aimed at reducing both the total harmonic distortion of the output voltage for all load conditions and the undesired oscillation phenomena during transient responses. The block scheme of the proposed control architecture is illustrated in Figure 5, where $\mathrm{G}_{4 \mathrm{~L}}(\mathrm{~s})$ is the TF of the inverter (1), $\mathrm{G}_{\mathrm{F}}(\mathrm{s})$ is the TF of the filter (2), $\mathrm{G}_{\mathrm{lf}}(\mathrm{s})$ is the TF of the second-order low-pass Butterworth filter defined in (3), $G_{R S C}(z)$ is the discrete TF of the resonant controller, and $G_{D O}(z)$ is the discrete TF of the DO. The gain $\mathrm{k}_{\text {gain }}=1 /\left(\mathrm{k} \cdot \mathrm{V}_{\mathrm{BUS}}\right)$, where $\mathrm{k}=0.57$. The designing and the tuning of the RSC is done at fundamental frequency of $50 \mathrm{~Hz}$, while the other harmonics are mitigated by the DO.

$$
G_{l f}(s)=\frac{\omega_{f}^{2}}{s^{2}+\sqrt{2} \omega_{f} s+\omega_{f}^{2}}
$$




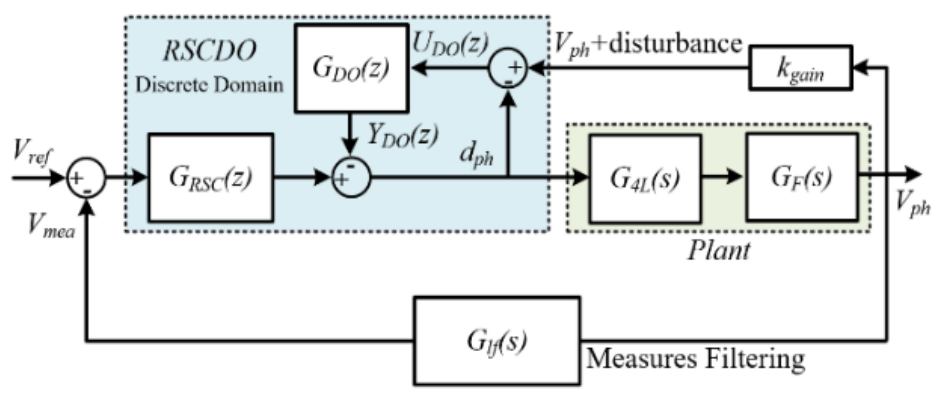

Figure 5. Block scheme of the proposed control algorithm

\subsection{Resonant controller}

The aim of the RSC is to regulate the voltage reference at a fundamental frequency with zero steady state error. Consequently, the RSC real form without the possibility of compensating the phase is chosen [27], [28]. In (4) the TF of the SRC is written, where $k_{\text {ir }}$ is the gain, $\omega_{\mathrm{cr}}$ is the controller width and $\omega_{0}$ is the resonance frequency.

$$
\mathrm{G}_{\mathrm{RC}}(\mathrm{s})=2 \mathrm{k}_{\mathrm{ir}} \omega_{\mathrm{cr}} \frac{\mathrm{s}+\omega_{\mathrm{cr}}}{\mathrm{s}^{2}+2 \omega_{\mathrm{cr}} \mathrm{s}+\left(\omega_{\mathrm{cr}}^{2}+\omega_{0}^{2}\right)}
$$

Taking into account that $\omega_{\mathrm{cr}}<<\omega_{0}$, the RSC amplitude at the resonance frequency is in (5), while the phase is equal to $0^{\circ}$ at the resonance frequency.

$$
\left|G_{\mathrm{RC}}\left(j \omega_{0}\right)\right|=\frac{2 \mathrm{k}_{\mathrm{ir}} \sqrt{\omega_{0}^{2}+\omega_{\mathrm{cr}}^{2}}}{\sqrt{4 \omega_{0}^{2}+\omega_{\mathrm{cr}}^{2}}} \cong \frac{2 \mathrm{k}_{\mathrm{ir}} \omega_{0}}{2 \omega_{0}}=\mathrm{k}_{\mathrm{ir}}
$$

The TF in the z-domain of the RSC $\mathrm{G}_{\mathrm{RSC}}(\mathrm{z})$ is written (6). This TF has been achieved using the Tustin with pre-warping technique [28]-[30].

$$
\mathrm{G}_{\mathrm{RSC}}(\mathrm{z})=\mathrm{k}_{\mathrm{RSC}} \frac{\mathrm{z}^{2}+\mathrm{a}_{\mathrm{RSC} 1} \mathrm{z}+\mathrm{a}_{\mathrm{RSC} 0}}{\mathrm{z}^{2}+\mathrm{b}_{\mathrm{RSC} 1} \mathrm{z}+\mathrm{b}_{\mathrm{RSC} 0}}
$$

The parameters of the DTF.

TF coefficients of the output power filter

$$
\begin{aligned}
& \mathrm{k}_{\mathrm{RSC}}=\frac{2 \mathrm{k}_{\mathrm{ir}} \omega_{\mathrm{cr}}^{2}+2 \mathrm{k}_{\mathrm{ir}} \mathrm{K}_{\mathrm{T}} \omega_{\mathrm{cr}}}{\mathrm{K}_{\mathrm{T}}^{2}+2 \mathrm{~K}_{\mathrm{T}} \omega_{\mathrm{cr}}+\omega_{0}^{2}+\omega_{\mathrm{cr}}^{2}}, \mathrm{a}_{\mathrm{RSC} 0}=\frac{2 \mathrm{k}_{\mathrm{ir}} \omega_{\mathrm{cr}}^{2}-2 \mathrm{k}_{\mathrm{ir}} \mathrm{K}_{\mathrm{T}} \omega_{\mathrm{cr}}}{2 \mathrm{k}_{\mathrm{ir}} \omega_{\mathrm{cr}}^{2}+2 \mathrm{k}_{\mathrm{ir}} \mathrm{K}_{\mathrm{T}} \omega_{\mathrm{cr}}}, \\
& \mathrm{a}_{\mathrm{RSC} 1}=\frac{4 \mathrm{k}_{\mathrm{ir}} \omega_{\mathrm{cr}}^{2}}{2 \mathrm{k}_{\mathrm{ir}} \omega_{\mathrm{cr}}^{2}+2 \mathrm{k}_{\mathrm{ir}} \mathrm{K}_{\mathrm{T}} \omega_{\mathrm{cr}}} \mathrm{b}_{\mathrm{RSC} 0}=\frac{\mathrm{K}_{\mathrm{T}}^{2}-2 \mathrm{~K}_{\mathrm{T}} \omega_{\mathrm{cr}}+\omega_{0}^{2}+\omega_{\mathrm{cr}}^{2}}{\mathrm{~K}_{\mathrm{T}}^{2}+2 \mathrm{~K}_{\mathrm{T}} \omega_{\mathrm{cr}}+\omega_{0}^{2}+\omega_{\mathrm{cr}}^{2}}, \mathrm{~b}_{\mathrm{RSC} 1}=\frac{2 \omega_{0}^{2}-2 \mathrm{~K}_{\mathrm{T}}^{2}+2 \omega_{\mathrm{cr}}^{2}}{\mathrm{~K}_{\mathrm{T}}^{2}+2 \mathrm{~K}_{\mathrm{T}} \omega_{\mathrm{cr}}+\omega_{0}^{2}+\omega_{\mathrm{cr}}^{2}}
\end{aligned}
$$

\subsection{Repetitive-controller-like disturbance-observer}

According to the state-space model of the disturbance $\mathrm{D}(\mathrm{z})$, the DO in [23] has been designed. Considering a periodic behavior of the disturbance $\mathrm{D}(\mathrm{z})$ with a frequency content at multiple of $\omega_{0}$, its dynamic model is written in (7), where $X_{d}$ is the disturbance state vector, $a_{33}$ is the matrix and $c_{d}$ is the vector. The matrix $a_{33}$ and the vector $c_{d}$ are given in (8). The instantaneous disturbance at $t_{k}$ is indicated as $D(k)$, while the vector $X_{d}$ is composed by $N=f_{s} / f_{0}$ elements, where $f_{0}$ is the fundamental frequency and $f_{s}$ is the sampling frequency. The meaning of (7) and (8) is that of a disturbance $\mathrm{D}(\mathrm{k})$ which is repeated for every $\mathrm{N}$ samples of measurement. Hence, the disturbance observer during the $\mathrm{k}^{\text {th }}$ sampling interval is obtained in (9). The equivalent measurement of the disturbance indicated as $U_{\mathrm{DO}}(\mathrm{k})$ is found by knowing the measured output voltage $\mathrm{k}_{\mathrm{gain}} \cdot \mathrm{V}_{\mathrm{ph}}$ at $\mathrm{t}_{\mathrm{k}}$ instant and the modulating voltage signal $\mathrm{d}_{\mathrm{ph}}$ required to be reached at $\mathrm{t}_{\mathrm{k}}$ instant.

$$
\begin{aligned}
& X_{d}(k+1)=a_{33} X_{d}(k) \\
& D(k)=c_{d} X_{d}(k)
\end{aligned}
$$




$$
\mathrm{a}_{33}=\left[\begin{array}{ccccc}
0 & 1 & 0 & \cdots & 0 \\
0 & 0 & 1 & \cdots & 0 \\
0 & 0 & 0 & \cdots & 0 \\
\vdots & \vdots & \vdots & \vdots & 1 \\
1 & 0 & 0 & \cdots & 0
\end{array}\right], \mathrm{c}_{\mathrm{d}}=\left[\begin{array}{lllll}
1 & 0 & 0 & \cdots & 0
\end{array}\right]
$$

In (9) the observer gains vector is indicated as $\mathrm{L}=\left[\mathrm{L}_{1}, \mathrm{~L}_{2}, . ., \mathrm{L}_{\mathrm{N}}\right]$, the estimated disturbance state vector is $\hat{X}_{d}$, the estimated disturbance at $t_{k}$ instant is $c_{d} \hat{X}_{d}(k)$, the observer matrix is $Q_{f}$ and the ratio between indirect measured disturbance at $\mathrm{t}_{\mathrm{k}}$ and the estimated disturbance at the same time is indicated as $\mathrm{A}$.

$$
\begin{aligned}
& \widehat{X}_{d}(k+1)=a_{33} \widehat{X}_{d}(k)+L\left[U_{D O}(k)-A c_{d} \widehat{X}_{d}(k)\right] \\
& Y_{D O}(k+1)=Q_{f} \widehat{X}_{d}(k+1)
\end{aligned}
$$

Based on (9), Figure 6 shows the schematic of the DO. The DO can mitigate the periodic harmonics like a repetitive controller is three assumptions are meet [23]: 1) the forgetting factor Q related to the RC is included if the matrix $\mathrm{a}_{33}$ is replaced into $\overline{\mathrm{a}}_{33}$ as shown in (10); 2) each value of the gains $\mathrm{L}$ are equal to zero $\mathrm{L}_{1}=\mathrm{L}_{2}=\ldots=\mathrm{L}_{\mathrm{N}-1}=0$ except for $\mathrm{L}_{\mathrm{N}}$; and 3) the role of stability filter used into repetitive controller in order to compensate the system delay is provided by the matrix $\mathrm{Q}_{\mathrm{f}}$.

$$
\overline{\mathrm{a}}_{33}=\left[\begin{array}{ccccc}
0 & 1 & 0 & \cdots & 0 \\
0 & 0 & 1 & \cdots & 0 \\
0 & 0 & 0 & \cdots & 0 \\
\vdots & \vdots & \vdots & \vdots & 1 \\
Q & 0 & 0 & \cdots & 0
\end{array}\right]
$$

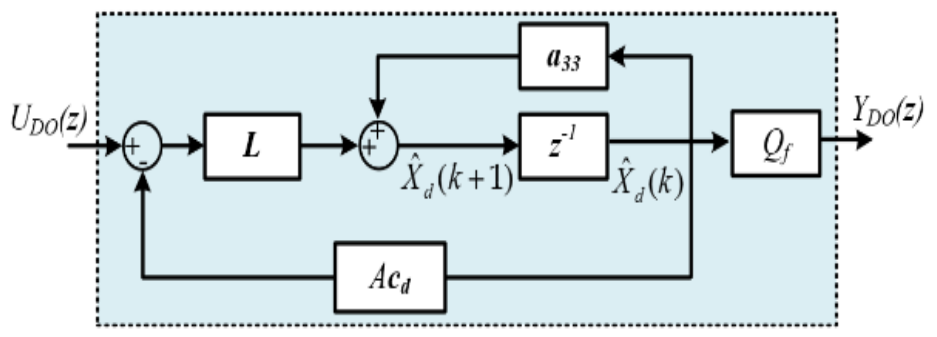

Figure 6. Block scheme of the DO

In this case, $\mathrm{Q}_{\mathrm{f}}$ is a $1 \times \mathrm{N}$ matrix with all zeros except the $\mathrm{i}^{\text {th }}$ element equal to one, where $\mathrm{i}$ is the total number of delays in the computation of $U_{D O}$. As a result, when the delay seen by the DO (i.e. the delay in the computation of $\mathrm{U}_{\mathrm{DO}}$ ) equals $\mathrm{M}$ sampling periods, the transfer function of the DO is as in (11).

$$
\mathrm{G}_{\mathrm{DO}}(\mathrm{z})=\frac{\mathrm{L}_{\mathrm{N}} \mathrm{z}^{-\mathrm{N}+\mathrm{M}}}{1+\left(\mathrm{AL}_{\mathrm{N}}-\mathrm{Q}\right) \mathrm{z}^{-\mathrm{N}}}
$$

To operate the DO, only two factors (i.e. the observer gain $\mathrm{L}_{\mathrm{N}}$ and the forgetting factor $\mathrm{Q}$ ) need to be tuned. The ratio $\mathrm{A}$, the length of the disturbance vector $\mathrm{N}$ and the length of the delay $\mathrm{M}$ are all known from the plant information. A Bode diagram based on (11) is illustrated in Figure 7 to demonstrate the nature of the DO and the influences of the two parameters, $\mathrm{L}_{\mathrm{N}}$ and $\mathrm{Q}$.

Generally, the DO can be understood as a filter that only very low frequency (like the DC component) and the integer multiple of $50 \mathrm{~Hz}$ can pass. The forgetting factor $\mathrm{Q}$ values between zero and one by definition. The larger the $\mathrm{Q}$, the larger the amplification to the pass-band signals. The observer gain $\mathrm{L}_{N}$ also affects the magnitude response. For stability reasons, the criteria derived in the next section need to be followed when choosing the two parameters. 


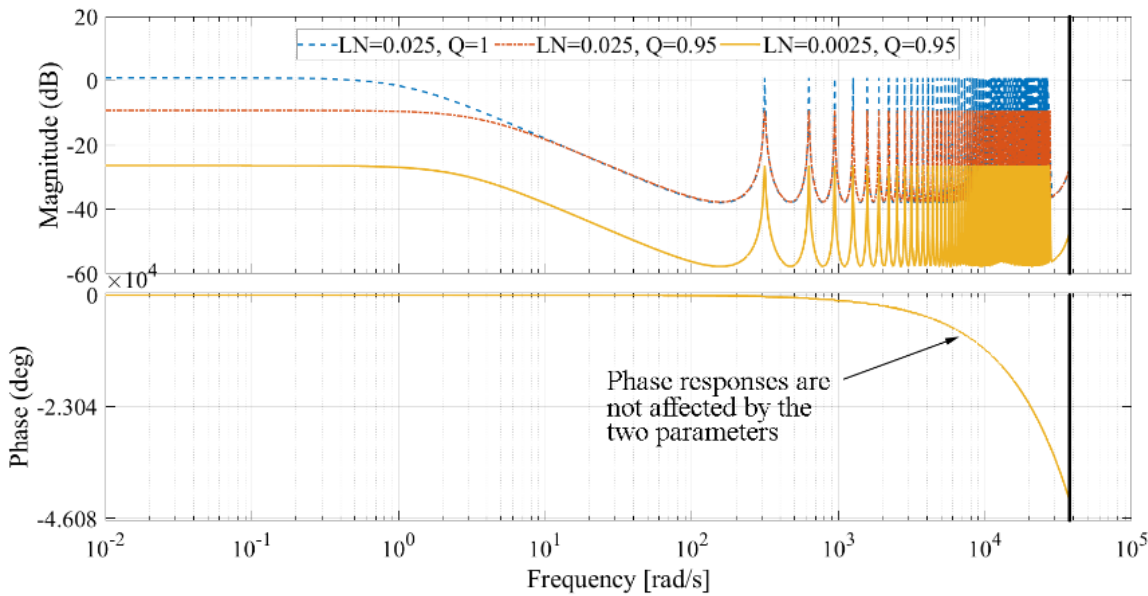

Figure 7. Bode plot of the DO with different gain $\mathrm{L}_{\mathrm{N}}$ and forgetting factor $\mathrm{Q}$

\subsection{Stability analysis}

To facilitate the stability analysis, the equivalent block diagram for Figure 5 is depicted in Figure 8, where $\mathrm{G}_{4 \mathrm{~L}}(\mathrm{z})$ and $\mathrm{G}_{\mathrm{F}}(\mathrm{z})$ are the discretized versions of the $\mathrm{G}_{4 \mathrm{~L}}(\mathrm{~s})$ and $\mathrm{G}_{\mathrm{F}}(\mathrm{s})$ in Figure 5 and $k_{\text {gain }}$ is defined in (1). A benefit of using the DO instead of the repetitive controller as in [14] is that it is easier to tune because of the separation principle. The DO can be tuned independently from the RSC; therefore, the stability can be assured if the system with only the DO loop and the system with only the RSC loop are both stable. Based on the small gain theorem, the stability of the system with only the DO loop can be ensured if the following criteria apply:

$$
\left|\frac{G_{D O}\left(e^{j \omega T_{s}}\right) G_{4 L}\left(e^{j \omega T_{s}}\right) G_{F}\left(e^{j \omega T_{s}}\right) k_{\text {gain }}}{1-G_{D O}\left(e^{j \omega T_{s}}\right)}\right|<1 \Rightarrow\left|\frac{L_{N} G_{4 L}\left(e^{j \omega T_{s}}\right) G_{F}\left(e^{j \omega T} s\right) k_{\text {gain }}}{1+\left(A L_{N}-Q\right) e^{-j N \omega T_{s}-L_{N} e^{-j(N-M) \omega T s}}}\right| \cdot\left|e^{-j N \omega T_{s}}\right|<1
$$

In summary, the system stability is ensured if the structure is stable without the DO, and the two parameters in the DO satisfy the stability criteria in (12).

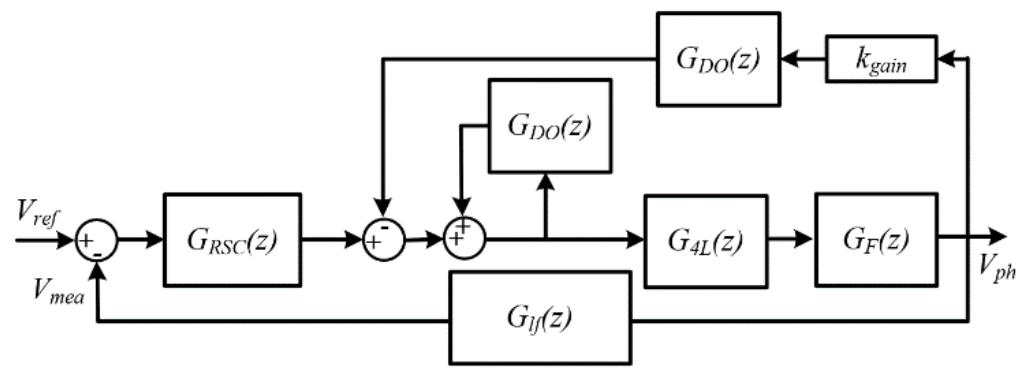

Figure 8. Equivalent block diagrams of the proposed control system

\section{SIMULATION RESULTS}

The model of the converter is created in Simulink to confirm the theoretical analysis. Simulation results have been evaluated according to the following operating point and system parameters: rated power $P_{n}=40 \mathrm{kVA}$, phase-to-neutral voltage $V_{x N}=230 \mathrm{~V}$, with $\mathrm{x} \in\{\mathrm{A}, \mathrm{B}, \mathrm{C}\}$, output fundamental frequency $\mathrm{f}_{0}=50$ $\mathrm{Hz}$, switching frequency $\mathrm{f}_{\mathrm{sw}}=12 \mathrm{kHz}$, dead-time equal to $2 \mu \mathrm{s}$, DC-bus voltage $\mathrm{V}_{\mathrm{BUS}}=400 \mathrm{~V}$, controller gain $\mathrm{k}_{\mathrm{ir}}=380$, controller bandwidth $\omega_{\mathrm{cr}}=0.01 \mathrm{rad} / \mathrm{s}$, vector length $\mathrm{N}=\mathrm{f}_{\mathrm{sw}} / \mathrm{f}_{0}=240$, forgetting factor $\mathrm{Q}=0.95$, DO gain $\mathrm{L}_{\mathrm{N}}=0.0025\left(\mathrm{~L}_{1}=\ldots=\mathrm{L}_{\mathrm{N}-1}=0\right.$ as in [23]), DO coefficient $\mathrm{A}=0.9$. The control strategy has been implemented in abc domain. The $\mathrm{Q}_{\mathrm{f}}=\left[\begin{array}{llllll}0 & 0 & 0 & 1 & \cdots & \mathrm{N}\end{array}\right]$ is selected to compensate the system delay. Figure 9 (a) and Figure 9 (b) show the the output voltages $V_{A n}, V_{B n}, V_{C n}$ and the related currents $I_{A}, I_{B}, I_{C}$ when the resistive load is used and DO is disabled. Figure 9 (a) and Figure 9 (b) illustrate that the waveforms of the voltage and the current are distorted during the zero-crossing due to the presence of mainly $5^{\text {th }}$ and $7^{\text {th }}$ harmonics (dead-time). Figure 10 (a) and Figure 10 (b) illustrate the output voltages $V_{A n}, V_{B n}, V_{C n}$ and the related currents $I_{A}, I_{B}, I_{C}$ when the DO 
is enabled. When the DO runs, the harmonics related to the dead-time are mitigated, as clearly shown in Figure 10 (a) and Figure 10 (b). When the DO is disabled and the three-phase diode bridge rectifier with capacitor filter $\mathrm{C}=1.5 \mathrm{mF}$ and load resistor $\mathrm{R}=25 \Omega$ is used as a non-linear load, the phase-to-neutral output voltages $V_{A n}, V_{B n}, V_{C n}$ and the currents $I_{A}, I_{B}, I_{C}$ are distorted, as shown in Figure 11 (a) and Figure 11 (b). Under some condition, when the DO is enabled the quality of both phase-to-neutral output voltages and the currents waveforms is greatly enhanced, as illustrated in Figure 12 (a) and Figure 12 (b). Thus, the joint RSC-DO enables to compensate the output voltage harmonics.

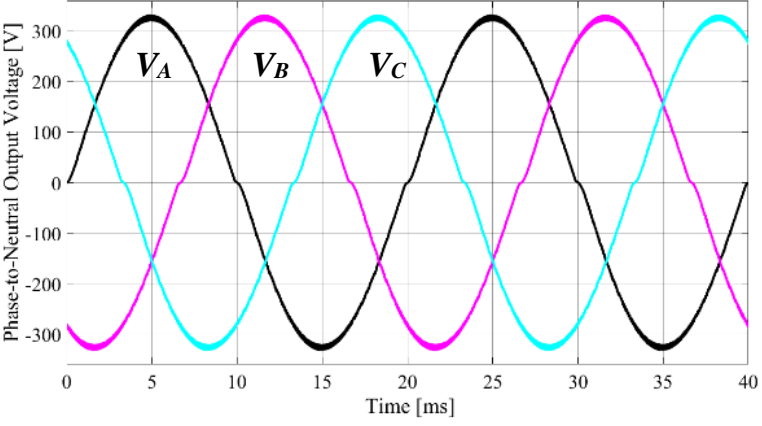

(a)

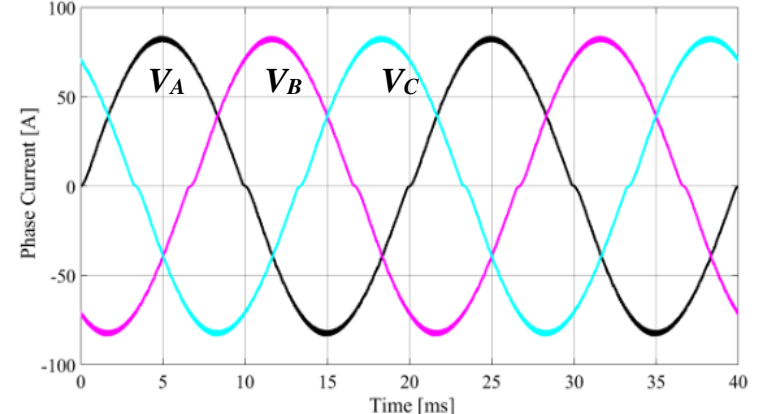

(b)

Figure 9. Waveforms when the DO is disabled and only the RSC runs in resistive load condition (a) phase-toneutral voltages $V_{A}, V_{B}, V_{C}$ and (b) currents $I_{A}, I_{B}, I_{C}$

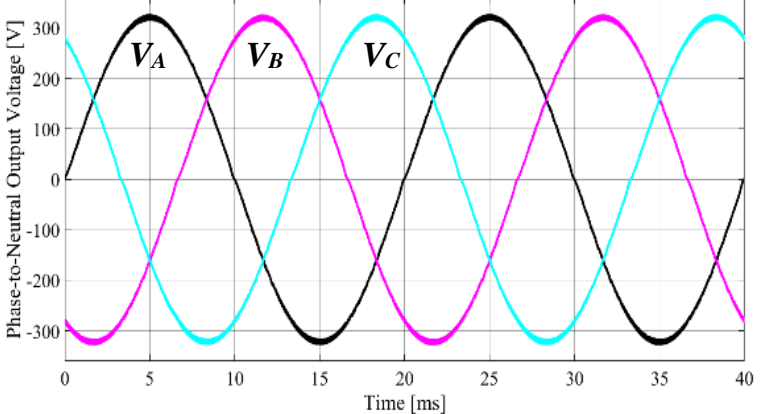

(a)

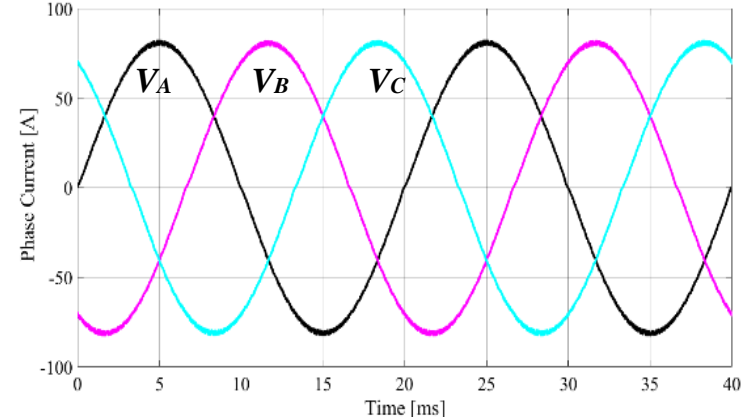

(b)

Figure 10. Waveforms when both RSC and the DO are enabled in resistive load condition (a) phase-toneutral voltages $\mathrm{V}_{\mathrm{A}}, \mathrm{V}_{\mathrm{B}}, \mathrm{V}_{\mathrm{C}}$ and (b) currents $\mathrm{I}_{\mathrm{A}}, \mathrm{I}_{\mathrm{B}}, \mathrm{I}_{\mathrm{C}}$

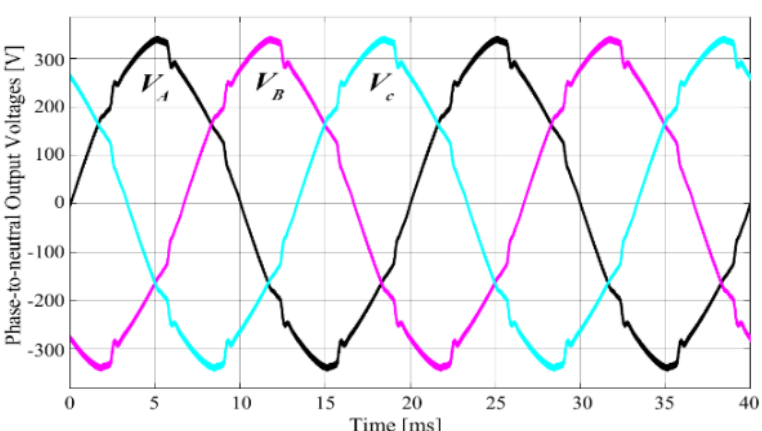

(a)

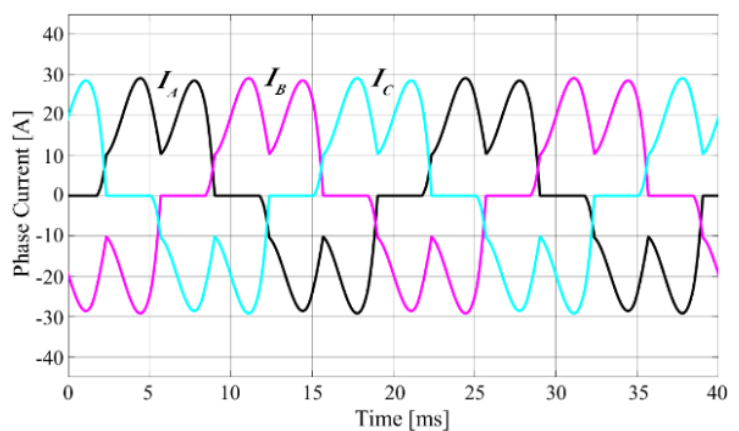

(b)

Figure 11. Waveforms when the DO is disabled and only the RSC runs in non-linear load condition (a) phase-to-neutral output voltages $V_{A}, V_{B}, V_{C}$ and (b) currents $I_{A}, I_{B}, I_{C}$ 


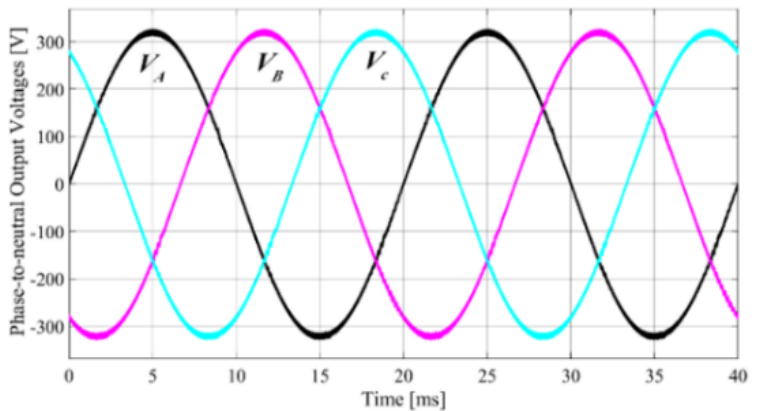

(a)

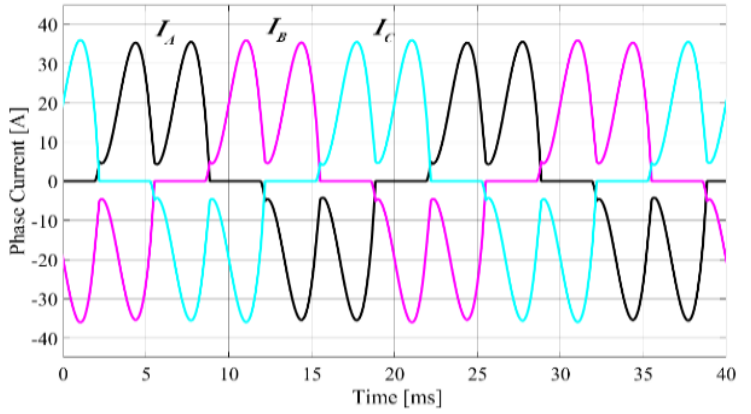

(b)

Figure 12. Waveforms when both RSC and the DO are enabled in non-linear load condition (a) phase-toneutral output voltages $\mathrm{V}_{\mathrm{A}}, \mathrm{V}_{\mathrm{B}}, \mathrm{V}_{\mathrm{C}}$ and (b) current $\mathrm{I}_{\mathrm{A}}, \mathrm{I}_{\mathrm{B}}, \mathrm{I}_{\mathrm{C}}$

\section{EXPERIMENTAL VALIDATION}

To evaluate the performance of the proposed control strategy and to validate the theoretical and simulation analysis, the prototype of the four leg VSI plus its three-phase output filter have been developed and tested. The experimental setup of the whole system is illustrated in Figure 13. Looking at the figure, it is possible to recognize the three-phase $4 \mathrm{~L}$ inverter, the output filter board and the control circuit which makes use of sbRIO-9651 system on module (SoM). The three-phase four leg VSI is illustrated in Figure 14. In the picture is highlighted the DC-bus capacitors, the driver circuit, the control circuit, the adapter circuit and the current sensors. A single leg is accomplished by using the SEMIX module (SEMIX303GB12Vs) 300 A $1200 \mathrm{~V}$. The main parameters of the converter are: VLL $=400 \mathrm{~V}$, fsw $=12 \mathrm{kHz}$, prated $=40 \mathrm{kVA}$, and VBUS $=750 \mathrm{~V}$. The three-phase $4 \mathrm{~L}$ VSI is fed by a programmable DC power supply. The voltage and current transducers (LV-20 p and LA-100 p) are used to sense both the output voltages and the phase currents. LabVIEW environment has been used to implement the control system. Experimental tests have been accomplished according to the operating point and system parameters listed in the simulation results section. A Yokogawa DL850 oscilloscope is used to analyze voltage and current waveforms. The proposed control strategy has been tested both under steady-state operating conditions and under transient conditions. The results in steady-state conditions are provided under four different load conditions: resistive load, no-load, unbalanced load, and non-linear load.

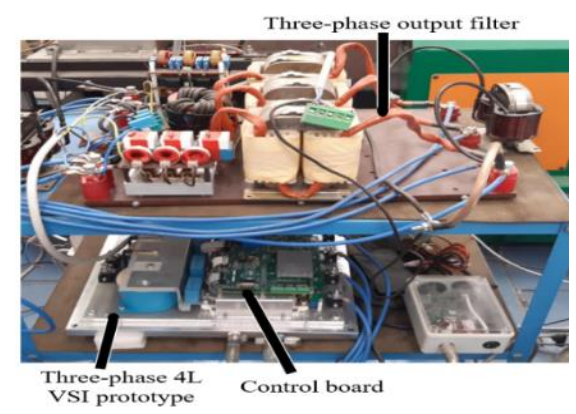

Figure 13. Experimental setup of the whole system

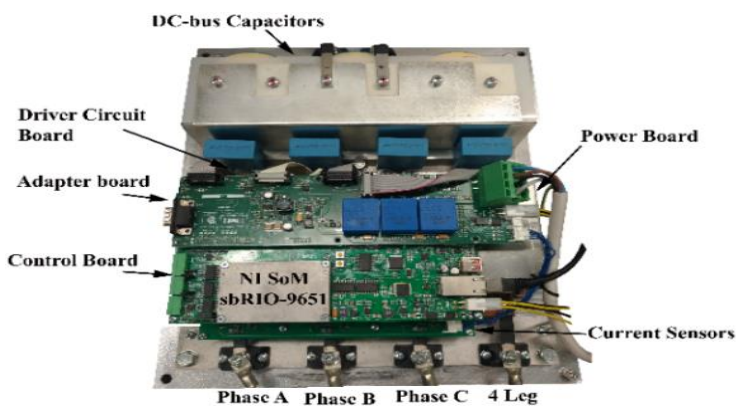

Figure 14. Three-phase 4L VSI prototype

\subsection{Resistive load and no-load condition}

During the preliminary tests the resistive load is set to $50 \Omega$, this means that the output power is equal to $3 \mathrm{~kW}$. The phase-to-neutral output voltages $\mathrm{V}_{\mathrm{An}}, \mathrm{V}_{\mathrm{Bn}}$, and phase current $\mathrm{I}_{\mathrm{A}}$ under resistive load condition are depicted in Figure 15. Figure 15 (a) shows the waveforms when the RSC and DO are enabled, whereas the DO is disabled in Figure 15 (b). Figure 16 shows the phase-to-neutral output voltages $V_{A n}, V_{B n}$, and phase current $I_{A}$ under no load condition, when the DO is engaged Figure 16 (a) or disabled Figure 16 (b). These results prove the good capability of the proposed control algorithm to perfectly compensate the harmonics introduced by the dead time between the switching devices. In fact, the phase-to-neutral output voltages show a small distortion at the zero crossing when the DO is disabled, as shown in Figure 15 (b) and Figure 16 (b). Thus, the DO can effectively compensate the low order harmonics (e.g. $5^{\text {th }}$ and $7^{\text {th }}$ order harmonics) in order to fully mitigate the dead time effect, as appears Figure 15 (a) and Figure 16 (a). 


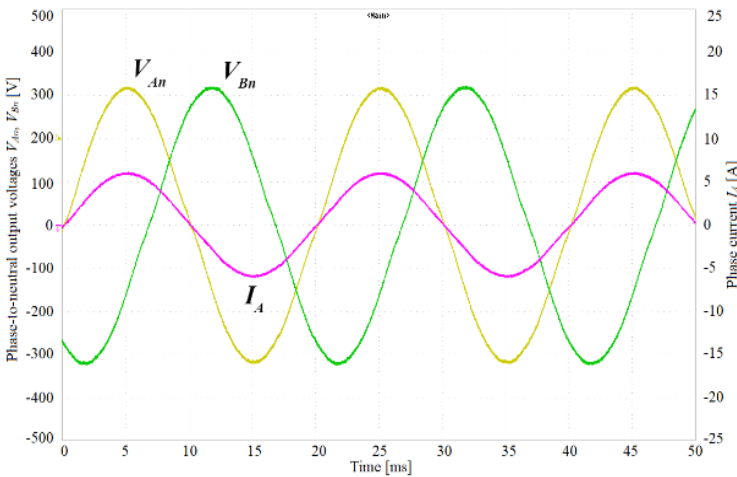

(a)

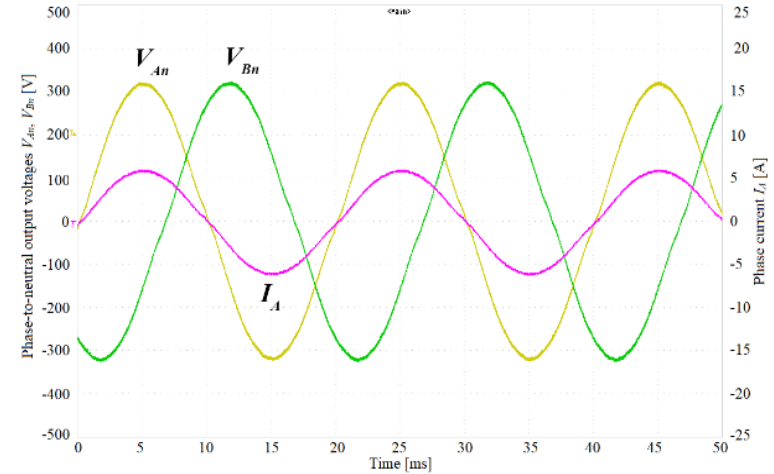

(a)

Figure 15. Experimental test in the resistive load situation (a) DO assisted RSC and (b) RSC without DO

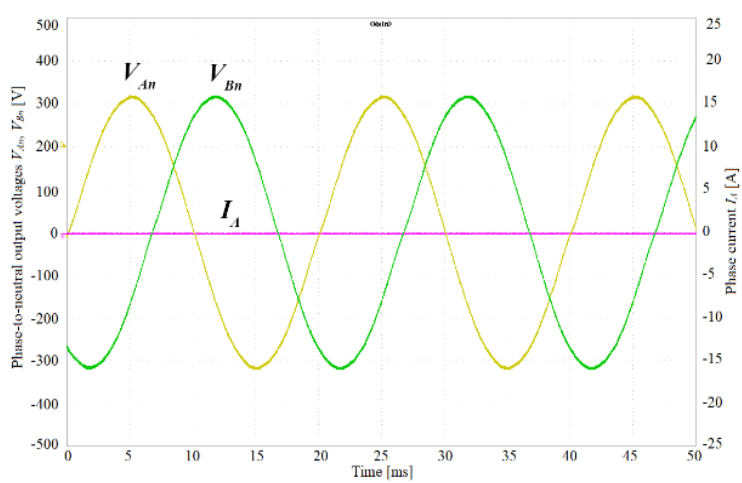

(a)

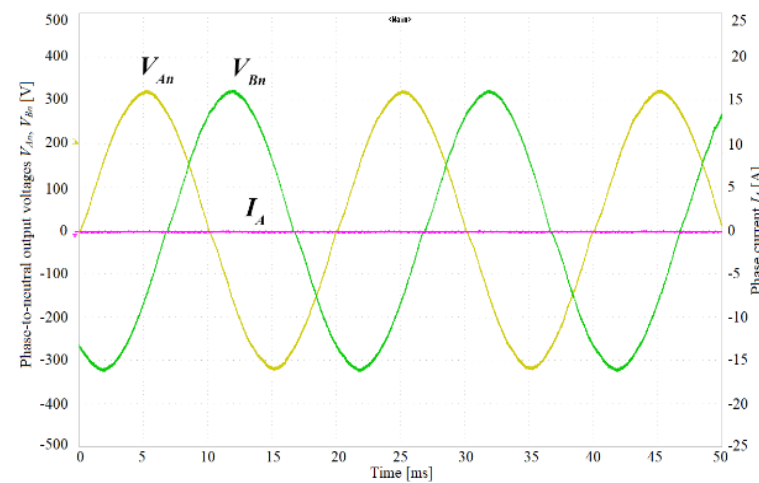

(b)

Figure 16. Experimental test in no load condition (a) DO assisted RSC and (b) RSC without DO

\subsection{Unbalanced load}

This test has been performed considering the phase a connected to the resistive load having the power equal to $1 \mathrm{~kW}$ while the other phases are open. Figure 17 illustrates the phase-to-neutral output voltages $V_{A n}, V_{B n}$ and the phase current $I_{A}$, in case of the DO assisting the RSC and when the RSC works alone. Looking at Figure 17 (a) and Figure 17 (b), it is possible to clearly distinguish how the DO adjusts the voltage waveforms and it is able to mitigate all the harmonics.

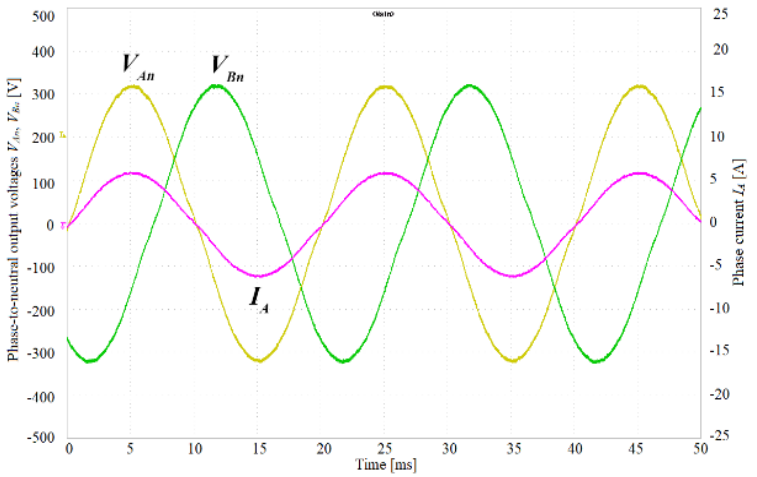

(a)

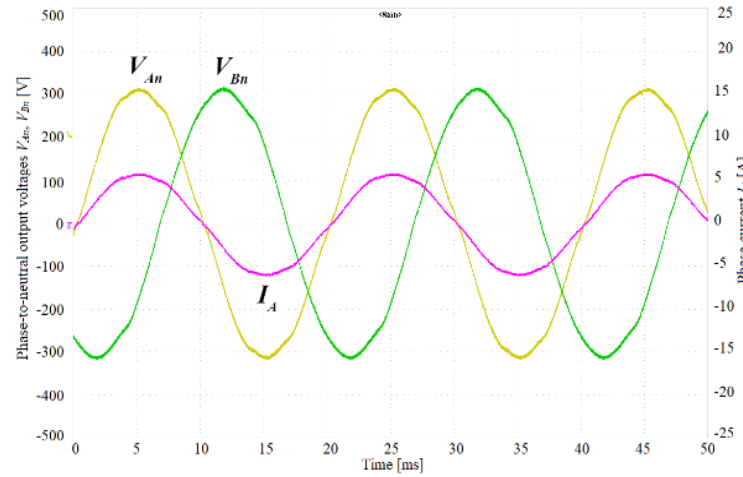

(b)

Figure 17. Experimental tests when one phase is loaded (a) DO assisted RSC and (b) RSC without DO

\subsection{Non-linear load}

Non-linear load tests have been carried out using a diode bridge rectifier with the capacitor filter $\mathrm{C}=1.5 \mathrm{mF}$ and load resistor $\mathrm{R}=25 \Omega$, as well as in simulation test. Figure 18 (a) and Figure 18 (b) illustrate 
the voltage waveforms $V_{A n}, V_{B n}$ and the current $I_{A}$, when the controller works with and without DO. Looking at the Figure 18 (a), it can be concluded that the DO is able to mitigate all the voltage harmonics, making the output voltages almost a pure sinusoidal waveform. Table 1 shows the total harmonic distortion, computed up to the $50^{\text {th }}$ harmonic order, of the phase-to-neutral output voltage when the DO is enabled and disabled in all the experimented load conditions. As it can be seen, when the DO is enabled the THD ${ }_{\mathrm{v}}$ is significantly reduced.

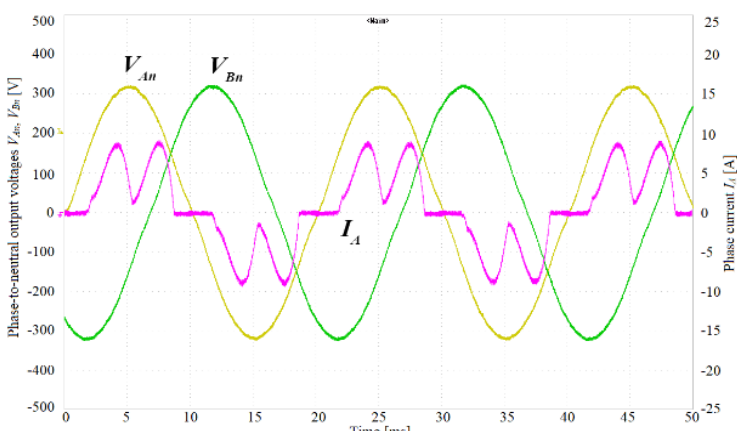

(a)

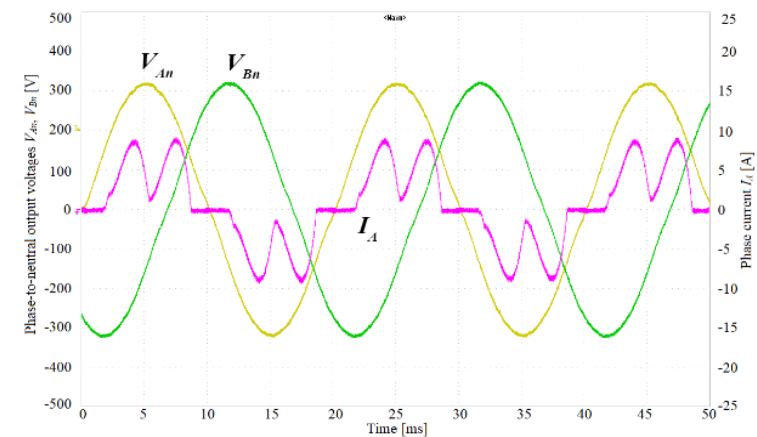

(b)

Figure 18. Experimental tests when non-linear load is used (a) DO assisted RSC and (b) RSC without DO

Table 1. Comparative total harmonic distortion of the output voltage

\begin{tabular}{lcc}
\hline & THD $_{\mathrm{v}}$ DO assisted RSC & THD $_{\mathrm{v}}$ RSC without DO \\
\hline Resistive Load & $0.38 \%$ & $1,97 \%$ \\
No-load & $0.57 \%$ & $2.48 \%$ \\
Unbalanced load & $0.91 \%$ & $4.31 \%$ \\
Non-linear load & $1.23 \%$ & $6.86 \%$ \\
\hline
\end{tabular}

\subsection{Transient response}

Further experimental tests have been carried out during transient conditions. The performance of the control strategy during a load step from $3 \mathrm{~kW}$ to no-load and back to $3 \mathrm{~kW}$ is illustrated in Figure 19 (a) and Figure 19 (b). It can be seen from Figure 19 that the load change is rapidly compensated by the DO assisted RSC and, thus, the output voltages are accurately regulated. The steady-state condition is reached after one and a half fundamental periods. Additionally, the maximum voltage drop during the load-step is less than 18 $\mathrm{V}$, which means that the overvoltage and the undervoltage remain below $5.6 \%$ of the nominal voltage. In this case, the proposed controller provides faster compensation in comparison to both the resonant-repetitive (RR) controller presented in [18] and the deadbeat and repetitive controller (DB-RC) in [19]. In fact, in [18], [19] the controllers take eight and five fundamental periods respectively to reach the steady-state condition.

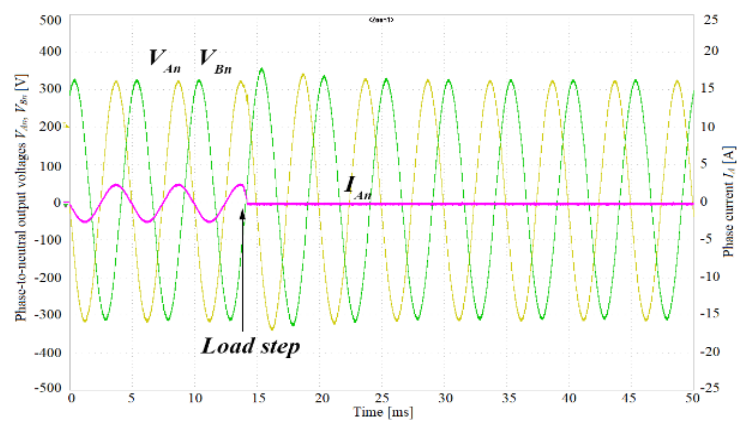

(a)

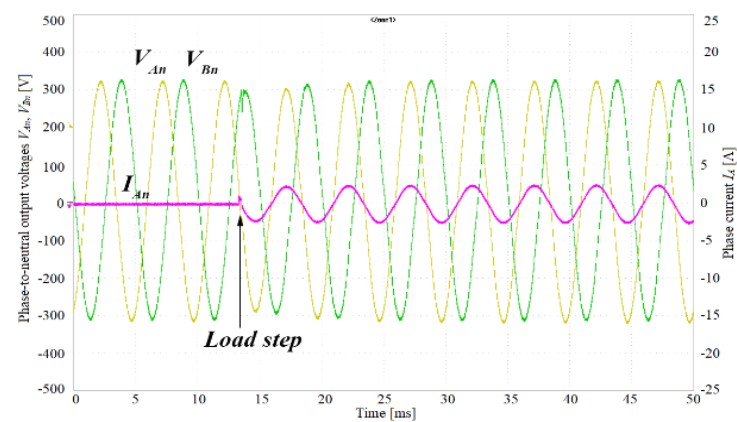

(b)

Figure 19. Transient response of the DO assisted RSC (a) load step from $3 \mathrm{~kW}$ to no-load and (b) load step from no-load to $3 \mathrm{~kW}$

Finally, Figure 20 depicts the voltages $V_{A n}, V_{B n}$ and the current $I_{A}$ during the initial step of the DO activation. The transient response after applying the DO takes one and a half fundamental periods starting from the point in which the DO is enabled. The RR, DB-RC, and RSC-DO controllers have been compared 
in Table 2 with reference to the transient time and maximum voltage drop during load-steps, as well on the basis of the phase-to-neutral voltage unbalance provided by the control and the $\mathrm{THD}_{\mathrm{v}}$ in the worse condition. These results demonstrate the good dynamic performance of the proposed control.

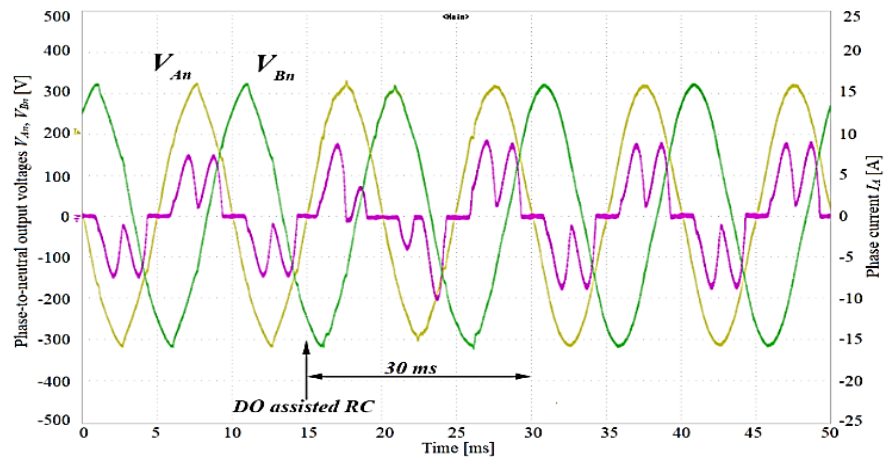

Figure 20. Experimental waveforms during the non-linear load condition at DO engaging

Table 2. Comparison RR, DB-RC, and RSC-DO controllers

\begin{tabular}{lccc}
\hline & RR & DB-RC & RSC-DO \\
\hline Transient time during load-steps & $160 \mathrm{~ms}$ & $100 \mathrm{~ms}$ & $30 \mathrm{~ms}$ \\
Maximum voltage drop during load-steps & $12 \mathrm{~V}$ & Negligible & $18 \mathrm{~V}$ \\
Phase-to-neutral voltage Unbalance & NO & YES & NO \\
Non-linear load THD & $1.7 \%$ & $0.5 \%$ & $1.25 \%$ \\
\hline
\end{tabular}

\section{CONCLUSION}

A new high-performance control approach for off-grud 4L VSI combining the RSC and the DO has been proposed in this paper. Motivations and requirements for a four leg VSI and its filter in stand-alone microgrids have been discussed. The stability analysis of the proposed control has been also performed and the results are described. At first, a digital model of the system has been created in MATLAB/Simulink environment to validate the proposed concepts in simulation. An experimental setup has been created and clearly described, as well as the proposed control strategy has been then implemented using LabVIEW environment. Experimental results are obtained in steady-state and transient conditions. The results show the effectiveness of the resonant controller jointly with the disturbance observer in improving the quality of the voltage waveforms in all load conditions.

\section{REFERENCES}

[1] L. B. G. Campanhol, S. A. O. da Silva, A. A. de Oliveira, and V. D. Bacon, "Power Flow and Stability Analyses of a Multifunctional Distributed Generation System Integrating a Photovoltaic System with Unified Power Quality Conditioner," in IEEE Transactions on Power Electronics, vol. 34, no. 7, pp. 6241-6256, July 2019, doi: 10.1109/TPEL.2018.2873503.

[2] M. Bajaj, A. K. Singh, M. Alowaidi, N. K. Sharma, S. K. Sharma, and S. Mishra, "Power Quality Assessment of Distorted Distribution Networks Incorporating Renewable Distributed Generation Systems Based on the Analytic Hierarchy Process," in IEEE Access, vol. 8, pp. 145713-145737, 2020, doi: 10.1109/ACCESS.2020.3014288.

[3] Y. Gui, R. Han, J. M. Guerrero, J. C. Vasquez, B. Wei, and W. Kim, "Large-Signal Stability Improvement of DC-DC Converters in DC Microgrid," in IEEE Transactions on Energy Conversion, vol. 36, no. 3, pp. 2534-2544, Sept. 2021, doi: 10.1109/TEC.2021.3057130.

[4] P. Prabhakaran and V. Agarwal, "Novel Boost-SEPIC Type Interleaved DC-DC Converter for Mitigation of Voltage Imbalance in a Low-Voltage Bipolar DC Microgrid," in IEEE Transactions on Industrial Electronics, vol. 67, no. 8, pp. 6494-6504, Aug. 2020, doi: 10.1109/TIE.2019.2939991.

[5] L. Kong and H. Nian, "Transient Modeling Method for Faulty DC Microgrid Considering Control Effect of DC/AC and DC/DC Converters," in IEEE Access, vol. 8, pp. 150759-150772, 2020, doi: 10.1109/ACCESS.2020.3017015.

[6] J. F. Patarroyo-Montenegro, F. Andrade, J. M. Guerrero, and J. C. Vasquez, "A Linear Quadratic Regulator with Optimal Reference Tracking for Three-Phase Inverter-Based Islanded Microgrids," in IEEE Transactions on Power Electronics, vol. 36, no. 6, pp. 7112-7122, June 2021, doi: 10.1109/TPEL.2020.3036594.

[7] A. F. Q. Gonçalves, C. R. Aguiar, R. F. Bastos, G. G. Pozzebon, and R. Q. Machado, "Voltage and power control used to stabilise the distributed generation system for stand-alone or grid-connected operation," in IET Power Electronics, vol. 9, no. 3, pp. 491501, 2016, doi: 10.1049/iet-pel.2015.0071.

[8] Q. Liu, T. Caldognetto, and S. Buso, "Review and Comparison of Grid-Tied Inverter Controllers in Microgrids," in IEEE Transactions on Power Electronics, vol. 35, no. 7, pp. 7624-7639, July 2020, doi: 10.1109/TPEL.2019.2957975.

[9] F. A. d. C. Bahia, C. B. Jacobina, V. F. M. B. Melo, and I. R. F. M. P. da Silva, "Low-Power Energy Conversion Systems with Two-Phase PM Machine and a Rectifier with Reduced Number of Controlled Switches," in IEEE Transactions on Industry Applications, vol. 52, no. 3, pp. 2332-2339, May-June 2016, doi: 10.1109/TIA.2016.2524407. 
[10] R. Li and F. Shi, "Control and Optimization of Residential Photovoltaic Power Generation System with High Efficiency Isolated Bidirectional DC-DC Converter," in IEEE Access, vol. 7, pp. 116107-116122, 2019, doi: 10.1109/ACCESS.2019.2935344.

[11] M. di Benedetto, A. Lidozzi, L. Solero, F. Crescimbini, and P. J. Grbović, "Low Volume and Low Weight 3-Phase 5-Level Back to Back E-Type Converter," in IEEE Transactions on Industry Applications, vol. 55, no. 6, pp. 7377-7388, Nov.-Dec. 2019, doi: 10.1109/TIA.2019.2928508.

[12] K. H. Youssef, "Power Quality Constrained Optimal Management of Unbalanced Smart Microgrids During Scheduled Multiple Transitions Between Grid-Connected and Islanded Modes," in IEEE Transactions on Smart Grid, vol. 8, no. 1, pp. 457-464, Jan. 2017, doi: 10.1109/TSG.2016.2577643.

[13] Y. Li, et al., "500 kW Forced Air-Cooled Silicon Carbide (SiC) Three-Phase DC/AC Converter with a Power Density of 1.246 MW/m3 and Efficiency >98.5\%," in IEEE Transactions on Industry Applications, vol. 57, no. 5, pp. 5013-5027, Sept.-Oct. 2021, doi: 10.1109/TIA.2021.3087546.

[14] A. Zama, A. Benchaib, S. Bacha, D. Frey, S. Silvant, and D. Georges, "Linear Feedback Dead-Beat Control for Modular Multilevel Converters: Validation Under Faults Grid Operation Mode," in IEEE Transactions on Industrial Electronics, vol. 68, no. 4, pp. 3181-3191, April 2021, doi: 10.1109/TIE.2020.2978708

[15] N. Kumar, T. K. Saha, and J. Dey, "Control, implementation, and analysis of a dual two-level photovoltaic inverter based on modified proportional-resonant controller," in IET Renewable Power Generation, vol. 12, no. 5, pp. 598-604, 2018, doi: 10.1049/iet-rpg.2017.0635.

[16] N. Marati and D. Prasad, "A Modified Feedback Scheme Suitable for Repetitive Control of Inverter with Nonlinear Load," in IEEE Transactions on Power Electronics, vol. 33, no. 3, pp. 2588-2600, March 2018, doi: 10.1109/TPEL.2017.2690361.

[17] K. Zhou, D. Wang, B. Zhang, and Y. Wang, "Plug-In Dual-Mode-Structure Repetitive Controller for CVCF PWM Inverters," in IEEE Transactions on Industrial Electronics, vol. 56, no. 3, pp. 784-791, March 2009, doi: 10.1109/TIE.2008.2005149.

[18] A. Lidozzi, C. Ji, L. Solero, P. Zanchetta, and F. Crescimbini, "Resonant-Repetitive Combined Control for Stand-Alone Power Supply Units," in IEEE Transactions on Industry Applications, vol. 51, no. 6, pp. 4653-4663, Nov.-Dec. 2015, doi: 10.1109/TIA.2015.2458960.

[19] A. Lidozzi, C. Ji, L. Solero, P. Zanchetta, and F. Crescimbini, "Digital Deadbeat and Repetitive Combined Control for a StandAlone Four-Leg VSI," in IEEE Transactions on Industry Applications, vol. 53, no. 6, pp. 5624-5633, Nov.-Dec. 2017, doi: 10.1109/TIA.2017.2734049.

[20] M. Ali, M. Yaqoob, L. Cao, and K. H. Loo, "Disturbance-Observer-Based DC-Bus Voltage Control for Ripple Mitigation and Improved Dynamic Response in Two-Stage Single-Phase Inverter System," in IEEE Transactions on Industrial Electronics, vol. 66, no. 9, pp. 6836-6845, Sept. 2019, doi: 10.1109/TIE.2018.2879294.

[21] Y. Zhu and J. Fei, "Disturbance Observer Based Fuzzy Sliding Mode Control of PV Grid Connected Inverter," in IEEE Access, vol. 6, pp. 21202-21211, 2018, doi: 10.1109/ACCESS.2018.2825678.

[22] Y. Wu and Y. Ye, "Internal Model-Based Disturbance Observer with Application to CVCF PWM Inverter," in IEEE Transactions on Industrial Electronics, vol. 65, no. 7, pp. 5743-5753, July 2018, doi: 10.1109/TIE.2017.2774734.

[23] M. Tang, A. Formentini, S. Odhano, and P. Zanchetta, "Design of a repetitive controller as a feed-forward disturbance observer," IECON 2016-42 ${ }^{\text {nd }}$ Annual Conference of the IEEE Industrial Electronics Society, 2016, pp. 78-83, doi: 10.1109/IECON.2016.7793242.

[24] H. M. Basri and S. Mekhilef, "Digital predictive current control of multi-level four-leg voltage-source inverter under balanced and unbalanced load conditions," in IET Electric Power Applications, vol. 11, no. 8, pp. 1499-1508, 2017, doi: 10.1049/ietepa.2017.0032.

[25] W. Zhao, X. Ruan, D. Yang, X. Chen, and L. Jia, "Neutral Point Voltage Ripple Suppression for a Three-Phase Four-Wire Inverter with an Independently Controlled Neutral Module," in IEEE Transactions on Industrial Electronics, vol. 64, no. 4, pp. 2608-2619, April 2017, doi: 10.1109/TIE.2016.2632678.

[26] G. Lo Calzo, A. Lidozzi, L. Solero, and F. Crescimbini, "LC Filter Design for On-Grid and Off-Grid Distributed Generating Units," in IEEE Transactions on Industry Applications, vol. 51, no. 2, pp. 1639-1650, March-April 2015, doi: 10.1109/TIA.2014.2345952.

[27] Z. Pan, F. Dong, J. Zhao, L. Wang, H. Wang, and Y. Feng, "Combined Resonant Controller and Two-Degree-of-Freedom PID Controller for PMSLM Current Harmonics Suppression," in IEEE Transactions on Industrial Electronics, vol. 65, no. 9, pp. 75587568, Sept. 2018, doi: 10.1109/TIE.2018.2793232.

[28] F. Hans, W. Schumacher, S. -F. Chou, and X. Wang, "Design of Multifrequency Proportional-Resonant Current Controllers for Voltage-Source Converters," in IEEE Transactions on Power Electronics, vol. 35, no. 12, pp. 13573-13589, Dec. 2020, doi: 10.1109/TPEL.2020.2993163.

[29] A. G. Yepes, F. D. Freijedo, J. Doval-Gandoy, Ó. López, J. Malvar, and P. Fernandez-Comesaña, "Effects of Discretization Methods on the Performance of Resonant Controllers," in IEEE Transactions on Power Electronics, vol. 25, no. 7, pp. 1692-1712, July 2010, doi: 10.1109/TPEL.2010.2041256.

[30] J. Ling, M. Rakotondrabe, Z. Feng, M. Ming, and X. Xiao, "A Robust Resonant Controller for High-Speed Scanning of Nano positioners: Design and Implementation," in IEEE Transactions on Control Systems Technology, vol. 28, no. 3, pp. 1116-1123, May 2020, doi: 10.1109/TCST.2019.2899566.

\section{BIOGRAPHIES OF AUTHORS}

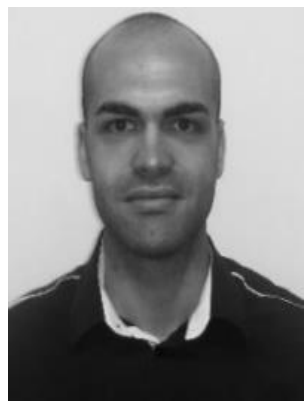

Marco di Benedetto (D) SC P received the M.Eng. degree in Electronic Engineering from the University of Roma TOR VERGATA, Rome (Italy), in 2014, and the Ph.D. degree in Mechanical and Industrial Engineering from ROMA TRE University, in 2018. Since November 2018, he is research fellow at Center of Power Electronics and Drives (C-PED) at the ROMA TRE University. His research interests are mainly focused on hardware and FPGA control design for multilevel power converter topologies. He can be contacted at email: marco.dibenedetto@uniroma3.it. 

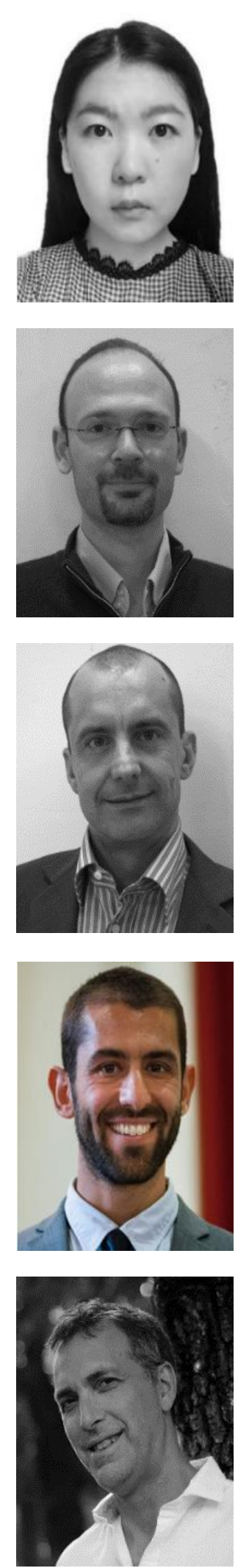

Mi Tang (iD) 8f SC P received the M.Sc. degree in electrical engineering and the Ph.D. degree in electrical and electronic engineering from the University of Nottingham, Nottingham, U.K., in 2012 and 2017, respectively. She is currently a Research Fellow with the Power Electronics, Machine and Control Group, University of Nottingham. Her research interests include deadbeat control, fault-tolerant control, and repetitive control. She can be contacted at email: mi.tang@nottingham.ac.uk.

Alessandro Lidozzi (D) SC S P received the Electronic Engineering degree and the Ph.D. degree from the Roma Tre University, Rome, Italy, in 2003 and 2007, respectively. From 2010 to 2017, he was Researcher with the Department of Engineering, ROMA TRE University; where, since 2017, he has been Associate Professor. His research interests are mainly focused on power converter modeling and control, control of permanent magnet motor drives, control aspects for power electronics in diesel-electric generating units, four-leg converters and development of high-performance control platforms based on combined DSP-FPGA systems. He can be contacted at email: alessandro.lidozzi@uniroma3.it.

Luca Solero (D) Id SC P received the Electrical Engineering degree from the University of Rome "La Sapienza," Italy, in 1994. Since 1996 he has been with the Department of Engineering, University ROMA TRE where he currently is a Full Professor in charge of teaching courses in the fields of Power Electronics and Industrial Electric Applications. His current research interests include power electronic applications to electric and hybrid vehicles as well to distributed power and renewable energy generating units. He has authored or coauthored more than 150 technical published papers. Since 2018, he serves as Vice-Chair the IEEE IAS Industrial Power Converter Committee IPCC. He serves as an Associate Editor of IEEE Transaction on Industry Applications. Prof. Solero is a member of the IEEE Industrial Electronics, IEEE Industry Applications, and IEEE Power Electronics Societies. He can be contacted at email: luca.solero@uniroma3.it.

Andrea Formentini (D) SC S S received the M.S. degree in computer engineering and the $\mathrm{Ph} . \mathrm{D}$. degree in electrical engineering from the University of Genova, Genova, Italy, in 2010 and 2014, respectively. He was a Research Fellow with the Power Electronics, Machines and Control Group, University of Nottingham. In September 2018, he became an Assistant Professor at the University of Nottingham. In 2021, Andrea joined the University of Oxford as a Lecturer in Engineering Science. He is currently assistant professor at the University of Genoa. His research interests include control of electric drives and power electronics. He can be contacted at email: andrea.formentini@unige.it.

Pericle Zanchetta (D) .81 SC P received his MEng degree in Electronic Engineering and his Ph.D. in Electrical Engineering from the Technical University of Bari (Italy) in 1993 and 1997 respectively. In 1998 he became Assistant Professor of Power Electronics at the same University. In 2001 he became lecturer in control of power electronics systems in the PEMC research group at the University of Nottingham - UK, where he is now Professor in Control of Power Electronics systems. He is also part time professor at the University of Pavia, Italy. He has published over 330 peer reviewed papers; he is past Chair of the IEEE-IAS Industrial Power Converter Committee IPCC and he is now Transactions review chair for IPCC. He is also Vice-Chair of the IEEE-IAS Industrial Power Conversion Systems Department (IPCSD). His research interests include control and optimization of power converters and drives, Matrix and multilevel converters. He is IEEE Fellow class 2019. He can be contacted at email: pericle.zanchetta@unipv.it. 